\title{
Alternative Assessment and Portfolios: Review, Reconsider, and Revitalize
}

\author{
Brian A Sandford ${ }^{1} \&$ Chia-Chien $\mathrm{Hsu}^{2}$ \\ ${ }^{1}$ Department of Technology and Workforce Learning, Pittsburg State University, United States \\ ${ }^{2}$ Department of Leisure and Recreation Management, Kainan University, Taiwan \\ Correspondence: Brian A Sandford, Department of Technology and Workforce Learning, Pittsburg State \\ University, United States. E-mail: bsandford@pittstate.edu
}

Received: February 13, 2013 Accepted: March 4, 2013 Available online: March 22, 2013

doi:10.11114/ijsss.v1i1.69

URL: http://dx.doi.org/10.11114/ijsss.v1i1.69

\begin{abstract}
The concept of evaluating performance in relation to an established objective is certainly not a new idea. The use and application of alternative assessments is likewise not a revolutionary notion. However, the mechanics and potential applications of the portfolio as one area of alternative assessment do deserve reconsideration with the purpose of a renaissance of this valuable and self-motivating type of formative and summative evaluation. The application of the portfolio to student, teacher, employment, and program areas provides the unique ability to assess performance based on selected work that demonstrates ability as well as potential. The ideal portfolio is a "living" document that allows individual expression of work while still meeting a uniform criterion of expected performance. In the same way that the benefits of student-centered over teacher-centered learning is being discussed, centering the assessment burden upon the student, teacher, employee, or program by providing the tools for authentic demonstration of their performance through the portfolio deserves another look.
\end{abstract}

Keywords: portfolio, alternative assessment, evaluation

\section{Introduction}

The demand for, and availability of, alternative assessment techniques for evaluating outcomes in the performance of people, programs, and businesses has become a reality for the professional, quasi-professional, and/or amateur evaluator. It is recognized that the discipline of evaluation is an evolving and maturing profession. However, and in consideration of evaluation's historical and integral relationship with education, the idea of alternative assessment in contrast to traditional standardized tests within the educational forum is causing and creating change. As such, a working rather than a superficial knowledge of the design, development, and use of alternative assessment strategies is important to function within the current discipline of evaluation, and may become a critical skill for future evaluators. The purpose of this paper is to provide: 1) background information on the alternative assessment ideology, and; 2) specific information addressing the design, application, and appropriateness of portfolios for evaluating teacher and student performance, representing oneself to a potential employer, and in assessing program effectiveness.

\section{Alternative Assessment}

The use of alternative assessment is not a panacea for the evaluator or for the evaluation discipline. As Worthen, et al. (1997, p. 51), states, "There is nothing wrong with that [mandating the use of alternative assessment in a particular program evaluation], unless such measures won't answer the evaluation questions posed or are too costly for the budget allowed for the evaluation." An obvious sine qua non for employing an alternative assessment technique or strategy is whether or not the alternative assessment strategy is appropriate and cost effective and therefore both usable and useful.

First and foremost in many minds might be, what is/are alternative assessment(s)? As Herman (1991) stated in a speech to the Consortium on Expanded Assessment, alternative assessment cannot continue to be a movement whose only definition is that, "it is everything that a multiple choice test is not" (cited by Worthen, 1993). Achievement in American schools has been routinely measured using standardized achievement tests. Several labels for the alternatives to these tests have been developed with the most common being direct assessment, 
authentic assessment, performance assessment, and the more generic term of alternative assessment (Worthen, 1993;Hancock, 1994; Worthen, et. al, 1997; Palm, 2008; Strijbos \& Sluijsmans, 2010; Frey, Schmitt, \& Allen, 2012). There are perhaps subtle distinctions in emphasis between these terms but they should be understood in the context of two commonalities. One, they are all viewed as alternatives to traditional multiple-choice student selected-answer tests, and two, they all refer to a direct examination process of student performance on significant tasks relevant to real-world applications (Worthen, et al., 1997; Worthen, 1993).

Are alternative assessment strategies new? Oral examinations, one variety of direct assessment, date back to the day of Socrates. In regards to the portfolio, elementary teachers have been keeping anecdotal "running records" of student work long before such tasks were legitimized, labeled, and refined by the recent development of the portfolio as a method to assess student progress (Worthen, 1993). Creative teachers could be accused of using "real-life" examples, peer assessment, and self-assessment for decades. Why the recent clamor for alternative assessment?

Demands for accountability in education during the early 1970's and the now famous "A Nation At Risk" report issued by the National Commission on Excellence in Education in the early 1980's, are a few of the causes which has made alternative assessment a major educational evaluation issue. State legislatures have for some time enacted laws that mandate the use of direct assessment of student performance as the means of determining how well schools, districts, and state education systems are performing (Worthen, 1993). For example, in 1995 Kentucky was to have the first statewide assessment system completely based on performance. It also goes without saying and is only mentioned briefly so as to not open the proverbial "Pandora's Box" that the No Child Left Behind Act of 2001 (PL 107-110, 2001) is the latest and most extensive effort at establishing educational accountability (Zatta \& Pullin, 2004). So although there is probably much that is unknown concerning alternative assessment, "Given the recent trends in the mandating of performance assessment by many legislative bodies and funding agencies, alternative assessment is unlikely to have the luxury of a decade in which to mature before being judged on its ability to solve some of education's thorniest problems, which themselves have had decades to develop, sometimes to gargantuan proportions" (Worthen, 1993, p.451).

Alternative assessment may also be considered part of the constantly evolving educational paradigm as well. Sormunen (1994) indicates that at the heart of the educational reform in America is the movement from a testing culture to an assessment culture. She also defines that authentic assessment, or assessing activities in a context similar to that encountered in real life, has resulted in an increased interest and awareness in nontraditional ways of assessing student progress and learning.

However, the future of alternative assessment could be threatened by its own popularity. The more widely it is accepted, the less frequently it will be challenged, and the more likely it will be that anyone who criticizes the methods or the application of alternative assessment will be accused of being "stuck in their old ways of doing things" if not an outright obstructionist standing in the path of progress. Additionally, it could only be hoped, for the sake of educational evaluation's professional reputation, that the rush to adopt alternative assessment is met with modest success. The consequences of a high-profile failure could be a serious setback to the alternative assessment movement (Worthen, 1993).

Secondly, will alternative assessment strategies be able to demonstrate that their assessments accurately reflect a student's true ability in significant areas of behavior relevant to the real-world. In other words, will alternative assessment strategies show that their tasks and measures are authentic and not just authentic looking?

The third issue is one of how evaluation professionals will react to the alternative assessment movement. As Worthen (1993, p. 445) states, "Many practitioners are unsure whether to venture into the torrents of unfamiliar assessment strategies or to drift quietly in education's backwaters, waiting to see if this movement crests and ebbs as quickly as have dozens of others." The evaluation profession, and education in general, has and will continue to dictate the forms and prevalence which alternative assessment will take in the near and distant future.

Finally, "The success of the alternative assessment movement must not depend on how effectively its most passionate firebrands carry out a scorched earth campaign against standardized testing. Ultimately, the success of alternative assessment will be judged by the persuasiveness of its internal rationales, rather than by external contrasts with traditional assessment" (Worthen, 1993, p. 446). What is being said here is this; it is up to the evaluation and educational profession to make alternative assessment work simply because the strategies work, not because they have comparative advantages over traditional testing.

There are many different types of alternative assessment methods and strategies such as rubrics, portfolios, performance scenarios, product assessment, peer assessment, oral examinations, interviews, group and individual projects, and formal and informal observations. Rubrics, for example, are simple scoring devices designed to 
assist in the process of clarifying and communicating expectations, and are basically grading templates which contain specific information concerning how the student can demonstrate performance and how teachers can assess their efforts. Performance standards are clarified by sharing the specific evaluation criteria as well as the various levels at which a student (or others) should perform (Custer, 1994; Nelson \& Drake, 1997). A rubric helps the person decide what they must do to meet the performance criteria, or in the case of the student, how they will be evaluated if they choose to perform at a given level of the evaluation rubric.

Another equally valuable but vastly different type of alternative assessment tool is the portfolio. The use and construction of portfolios is of particular interest in that they implement another of education's latest heralded methodologies of being student-centered vs. teacher-centered and the portfolio as an alternative form of performance assessment will be the focus of the remainder of this article.

\section{Portfolios}

The early and stricter definition of a portfolio was a portable case for carrying loose papers and prints and was usually associated with artists, journalists, or architects for the purpose of being able to show examples of their works. The term port means to carry and the term folio refers to a large collection of materials such as documents, pictures, papers, audio and video tapes, etc., relating to one or more dimensions of a persons' professional life. As the term is now generally being used and applied, a portfolio reflects a smaller collection of these same materials only selected for a particular purpose (Olson, 1991).

When the term, "portfolio," is applied for educational purposes, it refers to packages of materials which students or others assemble as a means of communicating their interests and abilities to others (teachers, peers, potential employers, parents, administrators, and others) (van Wesel \& Prop, 2008). Portfolios may contain a wide variety of materials and tasks including, but not limited to, photographs, drawings, technical reports, journals, testing results, teacher/student or supervisor/worker conferences, a resume, product or process assessment, check-off sheets, etc. (Custer, 1994). A portfolio provides a vehicle by which information-rich documentation of a person's progress and growth can be compiled over time. Portfolios provide an alternative to traditional assessment methods such as standardized tests which many critics believe do not give a complete picture of student achievement (Wildemuth, 1984; Hoepfl, 1993).

It should be recognized that portfolios are being employed as an alternative assessment method to standardized testing not solely because they provide summative evaluation information, but rather because portfolios also provide, and perhaps this is their true merit and worth, formative information during the evaluation period (Barrett, 2006). In other words, portfolios are not simply another means to an end in determining absolute performance, but are also tools for evaluating the effectiveness of the process and growth of the individual, program, or business. Whereas standardized tests rely on proxy items from which progress is inferred, portfolios are considered a more "authentic" assessment method because they can be used to examine performance in a naturalistic setting over time by evaluating an array of tasks that better mirror the process (Hoepfl, 1993).

The power of portfolio assessment is in its collaborative power, providing a common framework to discuss learning and achievement (Hoepfl, 1993). Portfolios weave together performance and assessment in a way that facilitates student, employee, administrator, etc. involvement in the process; therefore, people are more likely to find relevance and meaning in their school assignments, job requirements and program activities by being involved in the evaluation process. Higher levels of subject mastery may also result (Whichard \& Cobb, 1993).

Some guiding principles concerning a portfolio's content, development, and use as an alternative assessment strategy are helpful in understanding how and when to best use them. The following recommendations can help in their construction as well as their use:

- A portfolio is more than a collection of work, it should be a selection of work (Borthwick, 1995; Challis, 1999).

- Portfolios should be closely linked to the curriculum (job requirements, program design) using performance standards with clear expectations (Borthwick, 1995). Determining performance criteria can be a difficult task and requires an examination of "what is at the heart of any and all competent performance, without being tied to the specifics of a particular performance" (What do we want students to know?...and other important questions, 1992, in Hoepfl, 1993). Standard setting also should include agreement, based on an open discussion, between the parties concerning what is to be considered adequate performance. It is critical that most expectations be set out in advance so that individuals know what to work on or strive for over time (Borthwick, 1995), and; 
- Portfolios can lend content validity to the assessment since measured outcomes are the direct products of performing the work assignment, classroom task, or program function (Whichard \& Cobb, 1993). This is why it is helpful to ensure that the portfolio design, and its contents, are closely linked to the school curriculum, job requirements, and/or program design. Driessen, van Tartwijk, Vermunt, and van der Vleuten (2003) state that structure, coaching, and assessment are the crucial elements leading to the effectiveness of portfolios.

\subsection{Four Examples of Portfolio Types}

The following section will provide information on the types and kinds of strategies, information, and design of four types of portfolios; student, teacher, employment seeking, and program. These examples are not meant to provide a format or templates to be regarded as "official or accepted" portfolio designs or rules, but rather to provide some food for thought and perhaps incite some creative thinking.

\subsubsection{Student Portfolios}

First, what is a student portfolio? The Northwest Evaluation Association provides a good baseline definition in that a portfolio is a purposeful collection of student works that exhibits the student's efforts, progress, and achievements in one or more areas. The collection must include student participation in selecting contents, the criteria for selection, the criteria for judging merit, and evidence of student self-reflection (Paulson, Paulson, \& Meyer, 1991).

Basically, a student portfolio is a collection of work compiled by a student over time that demonstrates what they know or can do (Borthwick, 1995). It tells the story of the student's efforts, progress, or achievements in a given area (Hoepfl, 1993). Portfolios help to provide a broader base for assessing student achievement and in diagnosing their strengths and weaknesses. It can help students improve their performance by imparting some of the skills needed for them to become more articulate about expressing themselves as learners. As a result, students begin to take greater responsibility for their own education. "Perhaps the strongest benefit for students is that it encourages ownership of the learning process and makes the students aware of that process, rather than focusing on product alone" (Sormunen, 1994, p.10).

Portfolios are by their very nature dynamic. Their utility is based in large part upon this fact. However, there are three types of student portfolios identified by Grosvenor (1993), which may help the beginner to focus on the different ways a portfolio can be employed:

1. The showcase portfolio which highlights the student's best work;

2. The descriptive portfolio which demonstrates, but does not evaluate, student progress, and;

3. The evaluative portfolio in which all work is subject to evaluative criteria.

Finally, in illustrating the value of portfolios as a means for both teacher and student to understand the educational process at the level of the individual learner, Paulson, et al. (1991), provide the guidelines developed by the Northwest Evaluation Association at their 1989 and 1990 conferences on portfolio assessment. The following are some of those guidelines:

1. Since developing a portfolio offers the student an opportunity to learn about learning, the end product should contain information that shows that a student has engaged in self-reflection;

2. The portfolio is something that is done by the student and not to the student;

3. The portfolio is separate and different than the student's cumulative assessment records unless those records are relevant to the goals, objectives, and evaluation criteria of the portfolio;

4. The portfolio should contain information that illustrates growth. The growth must be discernable to both the student and the teacher.

There is one term which is prevalent in both the literature concerning portfolios as alternative assessment techniques, and in the Northwest Evaluation Association's definition of a portfolio and their portfolio assessment guidelines. The term is "self-reflection." Perhaps some additional coverage of this term and concept is merited, as the self-reflection process employed in the portfolio assessment method, is an important idea. Olsen (1991) states that the very act and nature of compiling a portfolio mandates reflective thinking and decision making. Hoepfl (1993) states that student reflection, or self-evaluation, of portfolio items is an essential part of portfolio assessment. Leske (1992, p.3) states, "The missing link in experiential learning identified by most people is reflection....[Students] who participated in structured reflection felt that they learned more from their experiences than those who did not have structured reflection built into their programs." Driessen, van Tartwijk, Overeem, 
Vermunt, and van der Vleuten (2005) show that portfolios can be used as a means of stimulating students to reflect on their experiences, particularly when the portfolio structure and materials are well organized and students are well coached.

To summarize this issue of self-refection in the use of portfolios, it is necessary to note that self-assessment is critical to the central idea of portfolios. While it may be the teacher's job to guide the process of producing the work and selecting the best examples, it is the student's job to learn the characteristics and features of good work, know what to look for when discriminating between examples of good work to include in the portfolio, and how to decide whether one item is a better representative than another (Borthwick, 1995).

\subsubsection{Teacher Portfolios}

A teacher portfolio, in much the same manner as a student portfolio, is a collection of work produced by a teacher to illustrate his or her talents, demonstrate their knowledge, a means of self-reflection, and an opportunity to critique their own work. An important aspect about teacher portfolios which is different than a student portfolio is their potential to be used in high-stakes decisions such as certification and advancement.

Doolittle (1994) indicates that the use of teacher portfolios for such high-stake decisions is not universally endorsed. Reasons for caution are the flexibility and subjectivity of the portfolio. First, the construction of the portfolio is such that each is a unique product, tailored to the individual. As a tool for professional development, this is a positive feature; however, using portfolios as a tool to arrive at personnel decisions is not recommended (Doolittle, 1994). The lack of standardization of portfolio contents, and the inability to use the portfolio as a comparative tool between teachers, is an obvious reason to exercise caution when determining a persons' professional teaching performance.

Second, the subjectivity in the evaluation of a portfolio is somewhat problematic. Given a portfolio's subjective nature, the issue of how the evaluation of portfolios can be made as reliable and valid as possible becomes important (Doolittle, 1994).As such, there needs to be an awareness that although teacher portfolios can take on much the same dimensions and formats as student portfolios, additional care must be taken in the way a teacher portfolio is evaluated and how the results are applied.

\subsubsection{Portfolios for Seeking Employment/Career Advancement}

Perhaps the recently graduating student from either secondary or post-secondary education who is toting a portfolio may actually have the edge when it comes to applying and interviewing for a job opportunity, or when seeking career advancement (Challis, 1999). Borthwick (1995, p. 26-48) states, "The potential of portfolio assessment extends beyond its contribution to student learning while in school. By helping students assess their own strengths and weaknesses and motivating them to produce polished work that meets explicit standards, portfolios are an excellent tool for teaching students to present themselves to a potential employer. A portfolio can become a student's passport to adult life."

A student that has compiled and been evaluated using a portfolio while in the terminal stages of their education may very well possess the right kind of information that perspective employers are looking for. Borthwick (1995) provides a good example of actual comments given by a small businessman participating in a focus group conducted by the New Standards project. The project is a partnership jointly run by the National Center on Education and the Economy, and the Learning Research and Development Center at the University of Pittsburgh. The purpose of the project was to find out what qualities business people look for in new employees. Following are the actual comments of one small businessman concerning his interview and hiring practices:

“'When I'm considering a kid for a job, I want him to be able to show me some examples of his school work, so I can see what his writing and math are like,' said the business man. 'If possible, I'd like to see a report on something he's done where he's had to take a lot of responsibility for his work. And I want him to be able to talk to me about his school work and anything else he has to show in a way that clearly represents him and what he can do....The trouble is, I don't see many kids who can present themselves like that. Usually, all they've got to show for their school work is a bunch of grades and, frankly, grades don't mean very much"” (Borthwick, 1995, p. 24)

The example illustrates the need for exploring the use of portfolios for seeking and advancing employment. Perhaps this application of the portfolio is one that has not been utilized nearly enough, nor has been given a chance to demonstrate its full potential. It is important to remember that a portfolio of school achievement and skill proficiency cannot be a retroactive endeavor. It must be built while in school, it cannot be hastily thrown together to attempt to represent oneself for a potential job. An effective and worthwhile portfolio begins with planning, construction, self-reflection, and evaluation early in a person's school or professional career, not as an 
afterthought. The school-to-work and tech-prep. Ideologies and efforts have long been with both educators and economists. It could and possibly should be speculated if these programs have either explicitly or inherently viewed the portfolio more closely for its unharnessed potential as an effective job hunting and interview tool. In the discussion of the ideas of seamless transition from secondary to postsecondary education or from degree completion to employment, articulation, workplace readiness, $21^{\text {st }}$ Century Jobs for $21^{\text {st }}$ Century Skills (U.S. Department of Commerce, U.S. Department of Education, U.S. Department of Labor, National Institute of Literacy, Small Business Administration, 1999), as well as other initiatives, the portfolio concept could be considered an essential ingredient to facilitate these transitions.

Lastly, Cole (1989) suggests that students assigned with preparing portfolios are actually motivated in their design and construction because of their potential use in job interviews and, administrators have been positive about the portfolio materials being an important factor in final employment decisions (cited in Olson, 1991). The potential use of a portfolio for future employment may be one of the motivational techniques a teacher can employ to encourage students in their portfolio preparation.

\subsubsection{Portfolios for Programs/Programming}

Sormunen (1994) concluded that the possibilities for using portfolios and/or the portfolio concept for employer purposes at the end of a training program were evident. In the same way that a student would use self-reflection to determine the important aspects of their education, an employee or program participant could use the same concept to provide feedback to their supervisor, the business, or program administrator concerning what aspects of their job, program function, or training experiences are relevant and effective. Business owners and program administrators should view the portfolio as one option to getting direct and relevant evaluative information concerning what works and what does not work within the administrative structure. As Sormunen (1994, p. 10) states, "...the possibilities for evaluation of an entire program [using portfolios] are apparent as well."

\section{Final Thoughts}

A portfolio's use and effectiveness, to some degree, will depend on whether it is being used as a tool for formative (in-process) or summative (at the end of instruction) assessment. In either case, it should be remembered that the value of portfolios as assessment tools ultimately depends on how carefully they are designed, maintained, and connected to objective criteria (or standards) which are relevant to the real-world setting in which they are taking place. "As with all assessment tools and techniques, they [portfolios] are designed to provide a means of clarifying and objectifying [sic] what it is that a student knows and is able to do. At the same time, portfolios have the distinct advantage of injecting rich, real-world data into the assessment process" (Custer, 1994, p. 83).

\section{References}

Barrett, H. C. (2006). Using electronic portfolios for classroom-based assessment. Connected Newsletter, 13(2), 4-6.

Borthwick, A. (1995). Body of evidence. With portfolios, students really show their stuff. Vocational Education Journal, 70(3), 24-26.

Challis, M. (1999). AMEE medical education guide No.11 (revised): Portfolio-based learning and assessment in medical education. Medical Teacher, 21(4), 370-386. http://dx.doi.org/10.1080/01421599979310

Custer, R. L. (1994). Performance based education. Implementation handbook. Columbia, MO: Missouri University. (ERIC Document Reproduction Service No. ED 379 459).

Doolittle, P. (1994). Teacher portfolio assessment. Washington, DC: The Catholic University of America. (ERIC Document Reproduction Service No. ED 385 608).

Driessen, E. W., van Tartwijk, J., Vermunt, J. D., \& van der Vleuten, C. P. (2003). Use of portfolios in early undergraduate medical training. Medical Teacher, 25(1), 18-23. http://dx.doi.org/10.1080/0142159021000061378

Driessen, E. W., van Tartwijk, J., Overeem, K., Vermunt, J. D., \& van der Vleuten C. P. (2005). Conditions for successful reflective use of portfolios in undergraduate medical education. Medical Education, 39(12), 1230-1235. http://dx.doi.org/10.1111/j.1365-2929.2005.02337.x

Frey, B. B., Schmitt, V. L., \& Allen, J. P. (2012). Defining authentic classroom assessment. Practical Assessment, Research, \& Evaluation, 17(2). Retrieved July 4, 2012 from http://pareonline.net/getvn.asp?v=17\&n=2 
Grosvenor, L. (1993). Taking assessment into our own hands. In M. Dalheim (Ed.). Student portfolios (pp. 9-16). National Education Association Teacher to Teacher Series.

Hancock, C. R. (1994). Alternative assessment and second language study: What and why? Washington, DC: Office of Educational Research and Improvement and US Dept. of Education. (ERIC Document Reproduction Service No. ED 376 695).

Hoepfl, M. (1993). Portfolio assessment. The Technology Teacher, 53(2), 28-29.

McCracken, J. D. (1993). Educating agriculturalists: New wineskins for new wine, Diamond Anniversary Lecture Series. Columbus: The Ohio State University, Department of Agricultural Education.

Morton, J. L. (1991). What teachers want to know about portfolio assessment. Tahlequah, OK: Northeastern State University. (ERIC Document Reproduction Service No. ED 336 728).

Nelson, L. R., \& Drake, F. D. (1997). Enhancing reflective practice through alternative assessment. Journal of Research in Rural Education, 13(1), 47-56.

Olson, M.W. (1991). Portfolios: Education tools. Reading Psychology, 12(1), 73-80.

Palm, T. (2008). Performance assessment and authentic assessment: A conceptual analysis of the literature. Practical Assessment, Research, \& Evaluation, 13(4). Retrieved May 15, 2009 from http://pareonline.net/getvn.asp?v=13\&n=4

Paulson, L. F., Paulson, P. R., \& Meyer, C. A. (1991). What makes a portfolio a portfolio? Educational Leadership, 48(5), 60-63.

Sormunen, C. (1993). Portfolios: An assessment tool for school-to-work transition. Business Education Forum, $48(4), 8-10$.

Strijbos, J., \& Sluijsmans, D. (2010). Unraveling peer assessment: Methodological, functional, and conceptual $\begin{array}{llll}\text { developments. Learning } & \text { Instruction, 265-269. }\end{array}$ http://dx.doi.org/10.1016/j.learninstruc.2009.08.002

U.S. Department of Commerce, U.S. Department of Education, U.S. Department of Labor, National Institute of Literacy, Small Business Administration (1999). $21^{\text {st }}$ Century Jobs for $21^{\text {st }}$ Century Skills (report No. 2003). Washington, D.C.: U.S. Government Printing Office.

Van Wesel, M., \& Prop, A. (2008). Comparing students' perceptions of paper-based and electronic portfolios. Canadian Journal of Learning and Technology, 34(3). Retrieved October 11, 2010 from http://www.cjlt.ca/index.php/cjlt/article/view/505/236

Whichard, J. A., \& Cobb, R. R. (1993). Assessment alternatives for students in vocational education. Fort Collins, CO: Colorado State University. (ERIC Document Reproduction No. ED 367 885).

Wildemuth, B. M. (1984). Alternatives to standardized tests. Princeton, NJ: ERIC Clearinghouse on Tests, Measurement, and Evaluation, Educational Testing Service. (ERIC Document Reproduction No. ED 286 938).

Worthen, B. R. (1993). Critical issues that will determine the future of alternative assessment. Phi Delta Kappan, 74(6), 444-456.

Worthen, B. R., Sanders, J. R., \& Fitzpatrick, J. L. (1997). Program evaluation: Alternative approaches and practical guides. New York: Longman.

Zatta, M. C., \& Pullin, D. C. (2004). Education and alternate assessment for students with significant cognitive disabilities: Implications for educators. Education Policy Analysis Archives, 12(16). Retrieved January 6, 2010 from http://epaa.asu.edu/ojs/article/view/171/297

\section{(cc) $\mathrm{Br}$}

This work is licensed under a Creative Commons Attribution 3.0 License. 